Perspective

\title{
Beauty care \& skin diseases treatment in Ayurveda
}

Volume 2 Issue 3 - 2015

\section{Facts about skin care}

Present scenario in context of beauty has been totally changed in every aspect. Our ancestral herbal beauty products like Haldi \& Chandan have been replaced by various chemical prone toxic \& costly cosmetic products. Beauty aspect is not just limited to females or younger generations now but it has been expanded to all the age groups in males and females both. Everyone today is beauty conscious as beauty or personality has moved one step ahead of personal and social front till corporate level (Figure 1). But irony is that people are getting just beauty conscious but not at all health conscious. They need to know that a person's beauty actually means beauty \& health of the skin which is the largest organ of our body both in terms of weight $\&$ surface area. It is the skin that protects our body from the germs, bacteria \& all other things spreading all around us. So, it is a kind of a protective shield (surakshakavach) for us. It also regulates our body temperature so that we can survive at various temperatures in various conditions.

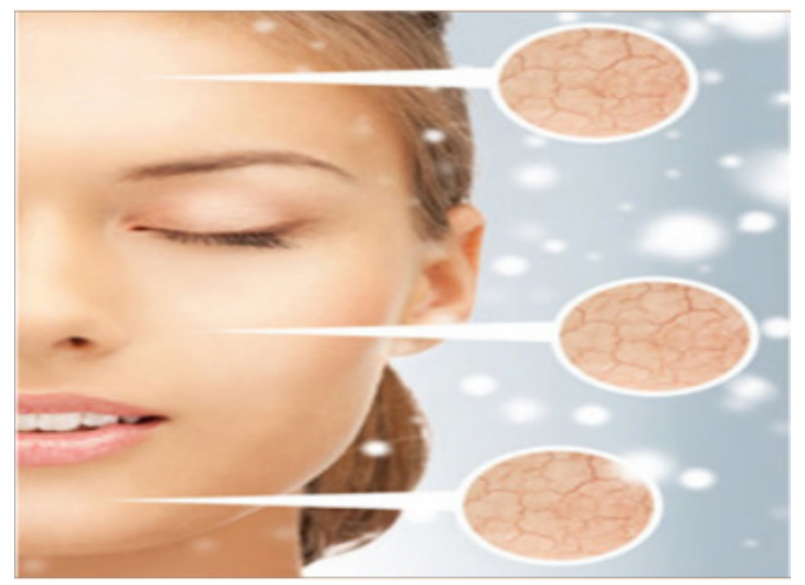

Figure I Dry Skin.

But with increased use of market available beauty products, skin problems are also increasing at a higher pace. Due to change in lifestyle $\&$ less availability of time, people are getting habitual of these easy \& less time consuming beautification procedures \& many big corporate are taking advantage of this and selling many toxic products on the name of herbal extracts. Our hard earned money is getting wasted in these harmful products which only cause damage to the skin. In short term, they give your skin an instant shine but slowly they start showing their dark side or you can say its side effects. Early ageing of skin is a very common example of it. These products not just steal the natural nourishment \& smoothness of the skin $\&$ make it dull \& dry but can lead to various kinds of other skin diseases also.

Some of the skin diseases can be normal \& easily curable with little care but it can be very dangerous \& incurable also like skin cancer. Common skin problems we face are acnes, pimples, pigmentation, blemishes etc. Biggest Concern here is that most of the times we take them as normal infection \& do home remedies to cure that. But delay in the treatment of these types of cases can lead to incurable or disastrous skin diseases.

\author{
Baldeep Kour \\ Deep Ayurveda, India
}

Correspondence: Baldeep Kour, Deep Ayurveda, H.N. I6IA, Dasmesh Nagar, Sector-16, Kharar, Mohali, India, Tel 9216582020 , Email deepayurveda@gmail.com

Received: December 29, 2015 | Published: December 30, 2015

Skin is the index of our body. Healthy skin represents healthy body. Any kind of skin problem indicates disturbance in some part of our body which need to diagnose properly to remove its root cause.

\section{Major causes of skin problems/infections/ diseases}

\section{Change in lifestyle}

It is the root cause behind any of our problem. Poor and hybrid dietary habits shift of all physical activeness \& burden to our mind has caused unhealthiness, stress \& hypertension. Biological clocks are not been followed for eating, sleeping. This uneven timing cause disturbance in body functioning because body follows its natural procedure. So, this creates digestion problem, \& many other problems, and skin disease is on the top of that list.

\section{Decreasing body's Nutritional level}

Due to poor diet, body suffers from nutritional loss. Lack of various essential nutrients like Vitamin A, B1, D, E weakens various major body parts like liver, heart $\&$ brain. Even absence of required amount of fat in the body causes dryness of skin which further generates many other skin problems.

\section{Poor quality blood}

Unhealthy lifestyle disturbs gastric functions inside the body due to which acid \& toxin level start increasing in our blood \& makes it acidic \& impure. This hampers the pure \& oxygenated blood supply to our skin \& other organs which in turn causes so many skin problems like acne, eczema, blemishes, etc.

\section{Disease attack}

Disturbed lifestyle \& dietary habits leads to various major diseases to our body like obesity, hypertension, diabetes, arthritis, piles, asthma which affects the whole body system. Skin is also a body part \& even a major part. So, how it left untouched from diseases.

\section{Hormonal problems}

Our poor lifestyle, increased stress \& anxiety majorly affect body hormones both in males \& females which in turn leads to various 
gynaecological diseases like PCOD \& menstrual problems in women $\&$ testicular disorders in males. These problems adversely affect our skin. Various infections \& skin related diseases occur for which people go to skin specialist instead of curing those gynecological disorders. This way not just your skin remained affected but also your gynaecological problems remained uncured.

\section{Age effect}

Now days, pace of aging has become fast. Technology has reached a level that people have forget that body is a natural thing \& will follow the nature's rule of age. During teenage, our sex hormones become very active which leads to increased oil secretion from the body that causes pimples and acnes. As we reached the age of 40's, activeness of these sex hormones becomes slower due to which dryness increases in the body. From that time, our skin starts getting wrinkles, patches \& many other disorders. At that time, we must not immediately rush to skin specialist or chemical prone medication as it adversely affects our skin. It is the natural procedure. We can't avoid it but we can lower down its pace by improving our lifestyle \& dietary habits or use good herbs to maintain the internal strength of the body.

\section{Excessive beautification}

Skin a thing which is most secure when left least untouched. It also need nourishment, massage but we have start using chemical prone beauty products which gives an instant shine to the skin but adversely affect it in long run. These products contain bleaching agents, Amino acid type harmful \& strong chemicals which is totally against the softness of our skin.

Due to all the above problems, people face various skin problems for which people start using tropical treatments like most commonly people visit skin specialists who suggest heavy anti-biotic, antiallergic \& anti-inflammatory. But in reality, they are not at all required as they just overburdened the Liver \& directly affect its functioning and health which in turn leads to many other serious problems. Our natural skin requires herbal nourishment \& treatment which is very light \& has no side effects.

\section{Steps need to be taken for healthy skin}

a. First and foremost requirement is to improve your lifestyle which is the root cause of every problem. Timely sleep \& diet will automatically cure various problems like stress, anxiety, early aging \& most importantly gynaecological issues.

b. Unwanted or excessive use of market available beauty products must be reduced to its lowest level as they steal natural smoothness, shine \& health of the skin (Figure 2).

c. Our body is a natural creation \& herbal, so herbal treatment is best suited to its requirement which tries to find the root cause of the problem \& then tear that root to give your skin everlasting effective treatment.

d. Nutritional level must be maintained of the body with the help of intake of nuts, sunlight \& various good herbs like Majishtha, methi which are easily available at home \& very useful for the skin.

e. Natural treatments must be given priority for beautification procedures like one can prepare purely herbal face pack at home by using various good herbs including some lentils like horse gram \& masoor. Skin massage can be done at regular intervals with good herbal oils like coconut oil, milk cream.

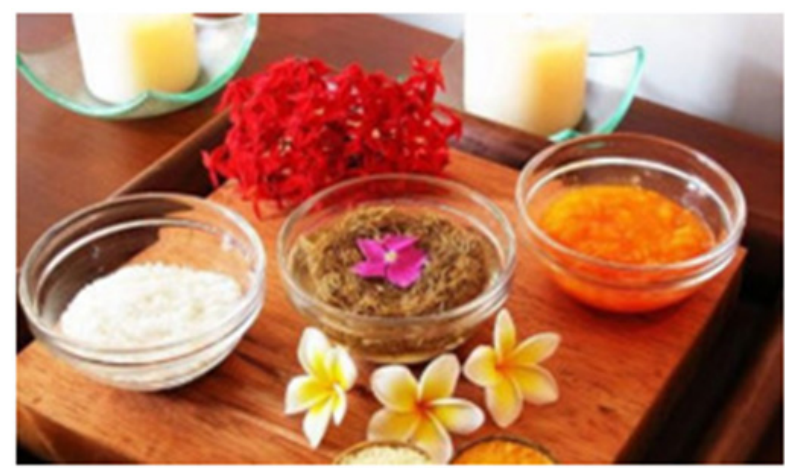

Figure 2 Herbal Beauty Products.

\section{What solution ayurveda provides for skin problems}

i. As we already discussed that skin is the index of body \& any skin problem has its link to a problem inside our body only. So, best \& everlasting treatment for any problem is to diagnose it rightly so that root cause can be found out. If the root cause will get solved, the skin related issues will resolve automatically (Figure 3).

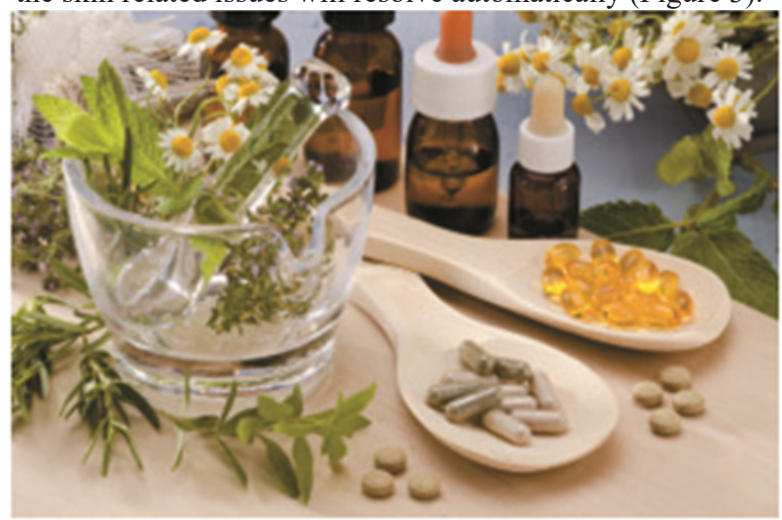

Figure 3 Ayurvedic Ingredients for Skin Problems.

ii. Ayurveda has its best solution in case of any kind of gynaecological problems or disorders which affect our skin. Ayurveda uses various time tested medicinal herbs to treat the affected areas as well as to provide strength to it for its proper functioning. This will result in smooth functioning of the body which ends in healthy skin. We must know that healthy skin survives in a healthy body only.

iii. Ayurveda provides some herbs which acts as nutritional supplement for the skin. These herbs makes the skin hydrated, provides essential nutrients \& strength to the body cells which includes face cells also and removes the dead cells or skin which creates infection or other problems to the skin.

iv. We at Deep Ayurveda Clinic having authentic and genuine Ayurvedic treatment for skin diseases and beauty care. We having classical \& Potent Ayurvedic medicines which are formulated with the time tested herbs and clinical researched by the team of our Ayurvedic doctor.

\section{Following ayurvedic formulations \& panchkarma therapies which are very beneficial for skin healthiness like}

1. Mahamanjistha Kwath 


\section{Khadiraristha}

3. Maha Sudarshanachurna

4. ChandraprabhaVati

5. ArogyavardhiniVati

6. Kaishore Guggul

7. Livclear Herbal Capsule \& Powder

8. Neem Juice

9. Aloevera \& Karela juice \& many others

Panchkarma treatment is a very renowned tool to cure many big problems. For skin related issues, Panchkarma has many therapies for skin protection and treatment like:

i. Virechan (very effective for skin)

ii. Vaman

iii. Swedan iv. Basti

v. Udvartan( scrub)

vi. Herbal face pack and

vii. Potli massage.

Our skin is a natural gift and it's our duty to take its care in a natural way only. Artificial products can only provide artificial or temporary shine \& glow, So give Ayurveda care to your body and skin.

\section{Acknowledgments}

None.

\section{Conflicts of interest}

None.

\section{Funding}

None. 